\title{
Re-vision, Re-tool, Re-spawn
}

\author{
Gameful Design for Whole-Person, \\ Transformational Learning \\ Chris Rosser, Oklahoma Christian University \\ Grant Testut, Oklahoma Christian University
}

ABSTRACT Gameful design challenges instructors to rethink course design for today's tech-saturated, pandemic-sequestered situation now that virtual is a crucial mode. We share two recent examples of gamification-curricular and co-curricular-demonstrating how gameful design yields whole-person, transformational learning. First, we describe our co-taught Bible and Classical Literature course, where hero-students journey into the dark, accomplish heroic tasks, earn badges, and engage desire-driven, side-quest learning. Second, we describe "Human Salvo: An Experiment with the Antidote to Zombification," a virtual, COVID-inspired alternative to weekly in-person chapel offerings. Chapel-as-game responded to our shared experience of Fall 2020, fraught with four anxieties: pandemic/contagion, political tribes, economy, and racial (in)justice (the primary anxieties that characterize zombie genre as well). Examples offer assessable evidence of learning toward specified outcomes. Our aim is to spark creativity among librarians-as-teachers for re-visioning, re-tooling, and (perhaps) re-spawning as gameoriented instructors.

\section{INTRODUCTION}

We begin with today's point: Gamified design is not mere child's play, but it is a return to the spirit of play that was present in the first seeds of liberal arts education. Gamification is an invitation to rethink instruction, especially in today's tech-saturated, pandemic-sequestered situation now that virtual is a crucial mode. Indeed, this article itself is a game-you are the hero of this brief journey together-and we invite readers to play along. (For a richer experience, please find our "Library Hero Personalities and Problem Solving” game online at http://bit.ly/libraryhero.) 
Also, note that segments of this paper are also available online as video recordings, and readers will likely find it more instructive and engaging to watch these videos; those interested will find links in the headings below. Between each segment, readers are asked to consider questions that will ultimately reveal your library-hero avatar. At journey's end, revealed avatars will help facilitate a final heroic challenge.

OK, ready to play? Here's the first question: Someone just insisted that the library should "gamify" all library instruction. How might you respond? (Note that following the link above reveals options that characterize responses to this situation. Use the link to play, or simply imagine your own likely response.)

Gamification is the application of game-design principles to nongame contexts; gameful design incorporates basic game architecture, story, and aesthetic as central to course design, infusing education with curiosity, imagination, and play. We want to share two new examples of gamification-curricular and co-curricular-demonstrating how gameful design yields whole-person, transformational learning.

\section{PROBLEMS WITH PLAY}

God said,

"The world is a play, a children's game, and you are the children."

God speaks the truth.

If you haven't left the child's play, how can you be an adult?

Without purity of spirit,

if you're still in the middle of lust and greed and other wantings, you're like children playing at sexual intercourse.

They wrestle

and rub together, but it's not sex!

The same with the fightings of mankind.

It's a squabble with play-swords.

No purpose, totally futile (Rumi 2004, 4-5). 
The startling thing about these words from the great Sufi mystic is that he levels them not at actual children playing games, but at adults who have convinced themselves they are done with playing games. Elsewhere in his writings, Rumi speaks of the sheikh who, in his wisdom, is to be found galloping on a stick-horse with children and not, as one would suppose, in a court of law or a teaching hall (Rumi 2004, 44ff). Thus we find in Rumi's poetry a paradox: on the one hand, he persuades his audience to put off play and become adults; on the other, he entices them to find wisdom in the simplest of children's games. It is hardly different when one comes at the matter through Christian scriptures. There we find Paul speaking of his maturity with the words "When I became a man, I parted with childish things." Elsewhere, the same author who derides playing kids games invites his audience to think of exemplary Christian conduct like the frivolities of foot racing and boxing. And let us not forget that one of the most endearing rebukes that Jesus of Nazareth has for his contemporaries is that they refused to play the games that Jesus himself and John the Baptist were inviting them to.

Here we find ourselves stuck in an ages-old identity crisis, one that echoes through the religious, academic, workaday, and domestic spheres of our lives-What is to be done with play? A part of ourselves tells us that it is time to have done with anything suggestive of idleness and lack of productivity. Another equally insistent corner of our being wonders whether we have had enough play to have made life worth the living. What we would like to share with you in this paper are some of our own jaunts into gamified learning, and what it has done to resurrect in a meaningful way the spirit of play in our students and in us as their teachers. We hope, by the end, that you will be able to see, first of all, that the daily routines we are accustomed to follow-religious ritual, the academic dance, information brokering - are already games that we have been playing, and sometimes poor ones at that. Secondly, we hope you will see the merits of embracing new forms of play for academia, the teaching of information literacy, and for religious dialogue.

\section{Excursus: Question 2}

Returning to our game, consider a second scenario: Your colleague suggests that "side quests" might be a beneficial way to develop information skills in students both within and outside the classroom. How might you respond to your colleague's suggestion? 


\section{PROPOSED SOLUTION: GAMIFIED LEARNING}

Gamified design is not mere child's play, but it is a return to the spirit of play that was present in the first seeds of liberal arts education. In this paper, we illustrate our assertion in three ways:

First, we describe our co-taught Bible and Classical Literature course, where hero-students journey into the dark, accomplish heroic tasks, earn badges, and engage in desire-driven, side-quest learning. Second, we describe "Human Salvo: An Experiment with the Antidote to Zombification," a virtual, COVID-inspired alternative to weekly in-person chapel offerings. And third, through the game we're playing together with you, reading a proceedings article as game. We hope this experience will be both informative and fun.

\section{Excursus: Question 3}

Let's consider a third question in our library-hero game. Here's the prompt: When talking about avatars in gaming, your colleague says, "Yeah, it's weird but playing as a confident character in a game, I find I have more confidence in my real-life interactions." How might you respond to your colleague's observation?

\section{EXAMPLE 1: GAMEFUL DESIGN IN THE CLASSROOM (BLIT)}

(Readers who prefer to engage the following as video will find it online at http://bit.ly/class-re-tooled.) Tertullian once quipped, "What indeed has Athens to do with Jerusalem? What concord is there between the Academy and the Church?" With these lines the ancient theologian addresses his concern over the reading of the so-called "pagan" classics by Christians of the second to third centuries, in addition to the accepted biblical canon of the Church. His desired rhetorical effect is immediately clear in the dismissiveness with which Tertullian asks his question: "What indeed has Athens to do with Jerusalem?" "Surely nothing!" has been the response that has practically echoed back among many Christian communities throughout the centuries. Nevertheless, such an easy answer has not been satisfying to many Christians who-likewise throughout the centuries-have found themselves drawn to and molded by the wisdom of great world literature, especially when read in conversation with their own sacred writ. And nowhere today is this matter more pressing than in faith-based institutions such as our own, where faculty 
and students alike take up the unenviable task of finding a "concord between the Academy and the Church.”

One honors-level class recently presented the two of us with just such a challenge. Affectionately dubbed "BLit" by our students, The Bible and Classical Literature is a long-standing OC offering that has students reading foundational texts from both the Bible and the greater classical world. The majority of our students have grown up in faith-based communities in which the Bible is upheld as the standard of both ontological truth ("reality") and societal truth (that with demands our "fidelity"). As helpful as these truth-claiming definitions may at first be, especially when seen in light of their service to the solidarity of the faith community, they can ultimately become a hindrance to doing what many Christian traditions pride themselves on doing: namely, reading the Bible. When the biblical texts are approached more like an instruction manual for life, this diminishes the cultural impact that they can have on humanity. They are stripped of their art and literary value, only to focus on their value as books of regulation and assertive postulates.

Along the same vein, many of our students were already acquainted with at least the SparkNotes version of such classics as those attributed to Homer and Virgil. But their all-too briefand never complete-reading of these masterpieces in high school exposes them only to the superficial details of their narratives, enough to know, say, that Greeks hated Trojans, that Odysseus got home, and that every single one of them believed in a laundry list of gods whom we all know now to be silly and antiquated (surely nothing like any of our current belief systems).

Thus, a lofty task was laid before us that would require some degree of Herculean effort: to get these students to read both the Bible and classical texts as literature, and as literature in conversation, at that. To do this would require the heroic feat of ascending the Olympian heights in order to bring the most sacred and lofty Bible down from its pedestal-not to diminish it, of course, but to read it (since books on pedestals are not for reading). It would likewise require a Dantean journey into Hell in order to retrieve the pagan classics from its infernal fires, dust off the accumulation of sulphur, and make them more readable, because less quickly condemnable. Such a broad journey between Heaven and Hell would require more heroism from us than we alone could muster. We would have to stand on the shoulders of giants. 
Who, then, could fill this role of teachers to the teachers? We would need to consult those who had some insights into both the habit-forming role of religious language and the culture-stretching role of literature. We finally decided upon everyone's favorite divergently thinking Christian scholar, C. S. Lewis, and on George Lucas' own Jedi Master, the man behind the myth, Joseph Campbell.

Many in Christian communities are familiar with the theological treatises of C. S. Lewis, looking upon him as an advocate for a type of Christianity that is critically engaged with the larger world. Even outside of Christian circles, it is hard to find anyone who has not heard of Lewis's famous children's series, The Chronicles of Narnia. Fewer are familiar with those of his works that address the technicalities of his discipline of literary studies. In one such work, The Abolition of Man, Lewis forms the argument that good literature must be judged, in part, on the merits of its connection to an almost inexpressible, invisible standard of what may be considered morally excellent and virtuous. Without being instructed in this, the student of literature will be trained to operate at the impulses of, alternatively, their stomachs—or baser instincts—and their brains, as informed by the academy. But they will not have been instructed in ways of the heart to judge what is deserving of our love and loyalty. They will be, to use Lewis's phrase, “men without chests.” Lewis attempts to prove the strength of his argument by demonstrating its universal applicability. He cites examples of language and theme throughout world literature that demonstrate commonly held concepts of truth, honesty, justice, compassion, and the like virtues. Though these systems of ethic go by different names- “righteousness" in Judaeo-Christian circles, dharma in Hinduism, ma'at in Ancient Egypt-Lewis elects to use the term "the Tao" to label this natural law implanted in the human conscience. Lewis perhaps chooses the Tao because it is so decidedly non-Christian. He so wishes to demonstrate his confidence in his conception of a universal, objective standard of what is morally excellent, that he purposefully chooses a name for it that comes from outside of his "tribal" camp. The two of us decided that exposing our students to The Abolition of Man, written by a household name in many Christian families, would endear to them the notion that truth-or, the Tao-can be met not only in the Bible, but in many non-Christian works of literature. (Interested readers should note that Barbara Brown Taylor's recent Holy Envy: Finding God in the Faith of Others provides an alternative to Lewis.) 
Joseph Campbell is a less well-known writer outside of the humanities, though any who have done enough digging into the inspirations from which George Lucas drew when creating the universe and plot of the modern epic Star Wars will know the great debt that is owed this scholar. Campbell's seminal volume, The Hero with a Thousand Faces, establishes a template of elements commonly found in epic story across the globe. The equation for these common elements, and the order in which they are almost always found, is known as the "Monomyth" or the "Hero's Journey." The central piece of Campbell's argument is that the most meaningful, epic stories met in cultures throughout the world retain these same elements of a hero's progression that include: (1) leaving the familiar (or "Status Quo"); (2) departing into the unfamiliar; (3) going through various trials, and possibly even death; (4) coming away from said trials with a treasure (or "boon"); and (5) returning home to share the blessings of this boon with society. The model for this journey itself, Campbell suggests, is based on the steps followed in any number of coming-ofage ceremonies: the initiate is first separated from the familiar and safe confines of home, is driven out into the unknown to meet with various trials (some of which are even connected with imagery of death), and then returns to society with the boon of sober reflections connected with adulthood. One way or another, the universal appeal of the hero's journey-in all its shapes and sizes-has to do with the fact that the audience to these stories lives vicariously through the testing of its heroes. Each of us learns to navigate the difficulties of life and to mature through these experiences by the examples laid before us in literature.

With these two voices-Lewis and Campbell-we now had a vocabulary to give our students that would help them structure their approach to the ancient texts. Lewis' Tao would open them to the possibilities of finding inspiration in both the Bible and classical texts, and Campbell's Hero's Journey would help them translate the gestures of the ancient Muses into something relatable to their own modern contexts. But having a vocabulary is not in itself a guarantee that our students would embrace this endeavor. The reading of the Bible in churches and synagogues, or of the Classics in the classroom and lecture hall, has not been enough to keep these lively pages from the deadening assault of stodgy formalism. One is reminded of the words of Jesus of Nazareth to those who did not appreciate the core of his message: 
To what, then, shall I compare the people of this generation? To what are they comparable? They are like children who sit in the marketplace and call to other children and say, "We played the flute for you, but you did not dance; we sang a dirge, but you did not weep"; for John the Baptist came neither eating bread nor drinking wine, and you say, "He has a demon!" The Son of Man came eating and drinking, and you say, "Look, a glutton and drunkard, a friend of taxcollectors and sinners." But wisdom is justified by all her children." (Luke 7:31-35)

And there it was, right in front of us the whole time: play! We needed to invite these students into a spirit of play, because play is what puts the mind in its most plastic and receptive state. We needed a gamified model of education to assist these students in their contemplation of foundational works of Western civilization, so that then they could understand the wisdom of these texts by playing along with them.

As a demonstration of the game we played, consider the following excerpt from an introductory video we created for students beginning the course:

Heroes, prepare. This semester, we embark on a journey both perilous and transformational: perilous because you will find yourselves challenged, stretched, ground, and sharpened against the whetstone of ancient and biblical texts; transformational because, by the end of our journey, you will likely find yourselves changed. Welcome to Bible and Classical Literature.

Think of Bible and Classical Literature as a game we're playing all semester, perhaps unlike courses you've experienced before. But be forewarned: calling our class a game does not mean it should be taken less seriously; on the contrary, the texts we will be engagingtimeless texts that make and keep us human-the texts, stories, characters, and truths you will encounter are deathly serious, texts like swords that divide bone and marrow, pricking hearts; texts like shields that protect, hardened by fire and emblazoned with markings of truth and struggle; texts like a healing balm, harbingering peace and quietness of soul.

Gamifying our course is a means for imbuing learning with curiosity, imagination, and play, not least because we humans are, after all, players, creatures-at-play, and all human activity is (or at least should be) infused with play. This will become more apparent in our class discussions; so for now, here's how the game works.

While the course meets three times weekly and moves linearly from task to task, activities and the course itself are suffused by the overarching model of Joseph Campbell's "Hero's Journey." His book The Hero with a Thousand Faces establishes a template of elements 
commonly found in epic story. Campbell's model describes a cycle that progresses through the following steps: leaving the familiar or "status quo"; departing into the unfamiliar; encountering various trials and possibly death; coming away from these trials with treasure or "boon"; and returning home to share to share that boon with the world.

The Hero's Journey model helps us adapt to a cosmos that is more terrible and beautiful than our minds can grasp. As we return to the model again and again throughout the course, you'll be asked to reflect on where you are and how you are feeling at various moments along our journey. These moments of reflection we're calling Heroic Tasks, and Heroic Tasks correspond to various hours on the journey.

Besides Heroic Tasks, before each class, you'll engage assigned readings; from the readings, questions will rise, and you will compose and post in the appropriate discussion forum a single ambrosial offering-a question of your own design, reflective of your own insight, and evidential of thoughtful engagement. Each ambrosial offering is a personal contribution to "feed" class conversation (ambrosia is divine food, of course, and student offerings help us savor and nourish ourselves through deep engagement with timeless texts).

Questions set the table for the feast of class meetings, fragrant ambrosial offerings that deeply satisfy, nourishing blood, bone, hearts, and minds, and with the catchword quest(ion)ing as driving force behind our hero's journey, students and instructors alike will employ inquiry as the primary mode for engaging biblical and classical texts.

So, recap: As a framework for conceptualizing our movement towards course completion, we are employing The Hero's Journey as a map to guide our undertaking. Throughout our journey this semester, you'll complete quest(ion)ing exercises and Heroic Tasks that serve to demonstrate comprehension of the texts we engage and competency with the thought-tools we're working to sharpen. Our questioning is an act of faith seeking understanding, and quest(ion)ing becomes sustenance for our quest, enlarging souls as we satisfyingly engage texts that make and keep us human.

But wait-oh, honored heroes, we know what you're thinking: Just tell me how to get an "A," that's all I need to know. Well, this is what you need to know: badges are awarded along the way, honors corresponding to successful completion of each Heroic Task; these badges culminate in the Hero's Badge, which signifies an " $\mathrm{A}$ " in the course. In other words, get the Hero's Badge by completing our quest, and you'll also get an A, your red badge of courage, perhaps. See our syllabus for details and further explanation. 
And our students were brave. They answered the call, and their reflective writings and in-class discussions demonstrated their courage to challenge their own presuppositions, as well as a willing vulnerability to admit what was new and scary for them to consider. Many came back out of those dark and mysterious realms of heroic introspection with their own unique boon. For some, it was clearly the ability to entertain new cultural perspectives without being quick to condemn or categorically dismiss, to see the humanity in any piece of literature. For others it was the newfound inclination to entertain the many perspectives that may be brought to an issue. For so long they had conditioned themselves to "gaming" the system of education to get their "A," that they had never entertained the idea of "playing" the game of learning. But these students demonstrated to us as their teachers not only that they had earned their respective grades, but that they had taken away something that can hardly be quantified. In the end, it was they who confirmed our beliefs that games are not just the stuff of children, but can be-as Huizinga put it so aptly decades ago in his work Homo Ludens-both "deadly serious" and "culture-forming." And that is the very stuff of education.

\section{Excursus: Question 4}

Before discussing gamified design in co-curricular spaces, let's consider the next question in our game. Your colleague suggests that information-seeking behavior should be guided by intrinsic rather than extrinsic motivations, and locating useful information is itself a kind of reward. How might you respond?

\section{EXAMPLE 2: GAMIFIED DESIGN IN CO-CURRICULAR DEVELOPMENT}

(Readers who prefer video will find the next segment online at http:// bit.ly/convergence-part1.) Here, we want to illustrate an approach to gamification—or what others call gameful design—by describing how we've employed this approach in both curricular and co-curricular learning spaces. We'll describe Beam Chapel, a weekly, co-curricular, spiritually formative event facilitated by Beam Library, and then show how COVID initiated an unanticipated convergence of co-curricular and curricular gamified learning.

At Oklahoma Christian University, students are required to participate in spiritually formative learning experiences, broadly defined, 
within our ETHOS program, a system developed by our Office of Spiritual Life for promoting, tracking, and assessing student spiritual development. One option for students is attending the various chapels facilitated by different departments or instructors, each with its own special focus to generate student interest.

By their participation in designated events or experiences like chapel, students earn Kudos, which are essentially points or tokens that signify attendance. So, you may be able to hear that this Kudos method is game-design-adjacent: earn a sufficient number of Kudos and satisfy Spiritual Life requirements, not least because of penalties visited upon those who neglect their Kudos. At the end of a semester no student wants the Eye of Sauron enthroned atop our Office of Spiritual Life to turn in their direction. But Kudos as tokens are indeed a gamified element of spiritually formative experience on our campus, and students keep track of earned Kudos on a special app accessed through their phones or computers.

Now, for seventeen semesters, Beam Chapel has intentionally offered a dynamic space for engaging gritty questions that impact faith and the culture(s) we inhabit, questions arising from the dark of film, literature, and television. Through chapel, librarians foster meaningful conversations and contribute to the University's spiritual mission of transforming lives for Christian faith and service. Semester themes are always second-commandment-driven: Beam Chapel exists at intersections of faith and popular culture as a reflective and questioning space where participants discern together how to enact the commandment to "Love the neighbor as the self." Beam Chapel is one option for interested students to earn required Kudos.

As you are very aware, in Spring 2020 everything seemed to fall apart as COVID closed campuses and disrupted our normed and conditioned modes of teaching and learning. By herculean effort in many cases, professors shifted course offerings online; likewise, libraries adapted and found new ways to virtually support learning and information access. But at Oklahoma Christian, our Kudos system collapsed! The semester was considered a wash; earned Kudos were suddenly devalued as the bottom fell out from our marketplace of spiritual formation. Students were left to their own devices, to be formed without Kudos, somehow, by whatever spiritual formation their own devices might afford.

These were desperate days. Yet out of the ashes Beam Chapel arose, a winged phoenix, clawed talons gripping fresh Kudos, co-curricular 
formation reborn! We determined to turn chapel into a game and offer virtual spiritual formation.

So, in Fall 2020, as contagion concerns canceled chapel-as-weknow-it, Beam Chapel's survival required a creative, new approach, incorporating robust virtual encounters that meaningfully formed and informed students toward better love of neighbor. We gamified chapel and launched our semester theme, Human Salvo: An experiment with the antidote to zombification.

As you remember, the moment we inhabited last fall was fraught with four primary anxieties: pandemic/contagion, political tribes, economy, and racial (in)justice. Fascinatingly, these are precisely the primary anxieties that characterize the zombie genre as well. So, we led with our semester's charge: In a moment suffused by zombification-dead(ly) force that turns people into things—our empathy is the true antidote, making zombies human. Our overarching ethic was empathy, and through chapel we intended to speak messages of loving neighbor as self into our present moment. Here's how it worked:

Our own approach to gameful design incorporates four elements: story, architecture (or structure), aesthetic, and elements. To gamify chapel, we created a storied world for students to inhabit: In Fall 2020, all our aims have been interrupted by an unforeseen global threat-you know, zombies! People becoming the walking dead, humans devouring humans. Society is a mess! E pluribus unum has rotted as everyone looks to their own tribe for protection. Needed goods are scarce-shopping malls have become haunts for dead-eyed eaters. The contagion is everywhere, and it's spreading; the prudent lock themselves in at home, venturing out only when there's no other choice. There's more to the story we were telling, but you can hear it resonating with students' real-life experiences.

So that's story; then we think about structure or architecture. We developed two videos each week. The first was a message from various faculty or staff who wanted to participate, who recorded a video message in-line with our story that communicated something about empathy. All videos were housed at a Google Slides we created for chapel, and each was accompanied by a brief prompt asking students to reflect and respond in 150 to 300 words. Students emailed their responses to an address we created for the chapelempathytheantidote@gmail.com—and responses earned the student a Kudo for chapel participation. Then, each week, just for fun, a 
second video was deployed, a video that continued or deepened the story, but that also offered opportunity to play chapel-as-game: these videos offered codes to break, or hinted at the location of secret objects hidden on campus-optional opportunities for students to enjoy escape into the storied world of zombification.

And this helps clarify the final two elements of gameful design we mentioned-aesthetics and elements. The aesthetic for our semester borrowed from familiar pop-culture zombie imagery (like our chapel poster) as well as plague-doctor imagery, which students encountered throughout, even in one professor who used a plague mask in her video on Toxic Positivity. Game elements involve the Kudo received for responses to weekly videos, and the side-quest nature of the non-required "game" aspects of chapel, like using a map to hunt around campus for artifacts infused with the energies of zombification.

So, you're wondering: How'd it go? Did the students love it? Did they enjoy this new mode for earning Kudos, this new vehicle for delivering virtually formative chapel? Well, it didn't go great, at least in terms of participation. We received only 60 responses for the entire semester to our weekly videos, and no student participated in any of the optional game elements, not even once. However, in terms of proof of concept, gamified chapel delivered, because we now had 60 learning artifacts related to co-curricular spiritual formation, students' own reflections on what they were hearing in the videos, how messages were shaping their thinking.

So now, let us describe how we approached Spring 2021 with a next-step idea to converge gamified co-curricular and curricular spaces, which dramatically increased participations and the number of assessable artifacts that we were able to collect.

(Readers who prefer video will find the following segment online at http://bit.ly/convergence-part2.) We introduce our next-step idea for gamified chapel by offering the opening bit of our introductory video:

Last Fall, Beam Chapel piloted virtual chapel as a precaution necessitated by COVID, grimly grappling the unproven, uncertain question Can virtual chapel be formative? So we launched Human Salvo: An Experiment with the Antidote to Zombification and achieved proof of concept: yes, virtual chapel can also be virtually formative, which we demonstrate with dozens of thoughtful responses to prompts from presentations throughout the semester submitted by students just like you. 
And you know how virtual chapel works: each week, a brief video message is dispatched, along with a prompt for reflection. Reply to the prompt and you get a Kudo for chapel, friend!

But is this tit-for-tat exchange of thoughtful reflection for a Kudo simply a banal tokenization of spiritual formation? Watch a fiveminute video, respond to the prompt in 150 words or so, and collect your heart piece? Well, I hope not; and much of that answer depends on you, dear student, and your willingness to engage the assortment of provocative video fare we assemble, all for your benefit. Oh, how I wish we were home, back together crowded in the dim space on the third floor of the Library where buzzy Beam Chapel once gathered, flesh and blood and bone squished in a sacred space for sitting thigh to thigh, unalarmed by quiet coughing in the back, mildly appreciative of showers of spittle raining out from an overly dynamic presenter, high-fives and laughter and a beeping scanner awarding Kudos-those were the days, my friends, and how I wish we were home once again, home like before!

Ah, nostalgia. Spring 2021, yet in the throes of COVID, Beam Chapel launches our second offering of fully virtual, virtually formative chapel. Our theme is Nostalgia: We Wanna Go Home. Nostalgia combines two Greek ideas, nostos (homecoming) and algos (pain); the loveliness of nostalgia masks the pain it bears, literally a pain felt for home.

This time, the overarching story is not nearly as developed or as immersive as the previous fall, when we inhabited a zombified dystopia. The theme, however, is rich and provocative, opening up lots of possibilities for presenters to offer their own ideas about or experiences of nostalgia. And we had numerous presenters sign up and create brief videos for student benefit and formation. As in the fall, videos were accompanied by a prompt for reflection, and students submitted responses for a Kudo. Aesthetic was communicated by our poster, imagery that suffused videos week to week. And game elements were similar-except for the side quest. That's where we discovered a change that made all the difference.

Spring 2021, Chris also taught a section of Acts of the Apostles for the first time; all new prep, which meant an interesting opportunity to think about gameful design. So he gamified the course by employing a non-linear path to course completion via modules "mapped" to the geography of Paul's missionary journeys, the geography of Acts. In other words, students were free to complete learning exercises in any order they liked; complete each region of the map or jump from 
here to there-students as traveler-heroes could follow their heart, as long as they completed one exercise each week.

But more significantly, Chris created a side-quest space for desiredriven learning, where participation leads to reward! The Nostos Algos forum is a virtual space where he posted non-required discussion threads, optional opportunities to stretch, challenge, and train beyond classroom conversations and out-of-class work.

Now, threads in the Nostos Algos were non-required in the sense that students could choose what they wanted to do or not do; but some participation in this forum was required. Per the syllabus, desire-driven learning was worth $10 \%$ of a student's grade. To get full marks for this aspect of grading, they needed 20 Nostalgia Points. Participation in this forum earns Nostalgia Points, and Chris tried to make the threads interesting. For example, there was a thread called "Our Journey's Playlist” for posting favorite songs that students found resonant with our travels through Acts.

And there was a thread that invited participation in virtual Beam Chapel, so that while earning Nostalgia Points students could also earn Kudos to fulfil Spiritual Life requirements.

Beyond a grade, participation in the Nostos Algos forum was incentivized by this move: earn 35 Nostalgia Points and you don't have to take the Final exam. Students were ready for the challenge, and many students earned 40,50, even up to 60 Nostalgia Points for desire-driven learning. The trick Chris discovered was to keep offered threads relevant and interesting, connecting classroom learning about Acts to our own here-and-now experiences. And as mentioned, virtual Beam Chapel was one option for desire-driven learning.

By semester's end, Chris had received about 60 responses-60 chapel participations-from students outside of his Acts class, which is similar to participation during the Fall semester. However, in total by the end of semester, there were 224 total participations in virtual chapel, which means that there are 224 submitted reflections to weekly prompts, each between 150 and 300 words-qualitative, assessable data for showing the formative value of virtual chapel. We were very surprised not only by the level of participation, but especially by the quality of reflections submitted. Nostalgia as a theme stirred something powerful in these students, who shared insights and memories and the pain of their own experiences of home. Students were making the ethical connections we had hoped 
for, and responses were infused with empathy and electrified by love for neighbor as the self. So kudos to these students-yes, the token Kudo for participation in chapel, but also kudos to these students for showing and sharing what's inside of them, exemplifying through reflection how virtual chapel can nevertheless be virtually (if not actually) spiritually and ethically formative.

\section{Excursus: Question 5 and reveal}

Here at the end we return to our game. Here's the next prompt: Your colleague suggests that attendance is a means for tracking participation, but attendance itself tells us nothing about learning or formation. How do you respond?

We've illustrated gamified learning in both curricular and co-curricular spaces-precisely the spaces librarians inhabit, at the intersection of in-class and out-of-class experiences that characterize the role of the library on our campuses. So, library hero, what personality are you? For this game, we created five library-hero avatar types-which hero are you? Are you:

THE RESEARCHER, a collector and protector of information. If so, this may indicate that you are quintessentially a librarian, library-hero!

THE ADVOCATE, a library-hero who's always ready to throw down when student safety or emotional wellbeing is at stake-a truly heroic type!

THE RULE BREAKER who doesn't just move to the beat of your own drum—no way, you brought a gong! You're a rule breaker, library hero!

THE SCHRUTE, which, yes, is unapologetically a reference to The Office, and Dwight Schrute brings the most out-of-the-box thinking to bear (get it? to bear...?). Crazy. But ya know what? It's so crazy, it just might work... That's the Schrute!

Or are you THE MASHUP because your responses map to several different "types” of library-hero! Nobody's gonna pin you down or put you in a box! 
Your avatar is a reflection of you, only intensified-taken to the furthest heroic degree! We're going to describe a situation and opportunity for more heroic questing. Consider how you might respond to each of the following scenarios as we enter the dungeon, library heroes!

University Administration has asked the library to find a means for better assessing information literacy, since info and media literacy skills are important for the kind of graduates we want our students to become. You realize there are only two viable options before you: You might set up a meeting with a couple of administrators to hear what they have in mind; or, you could consult the mystic Oracle who lives in the fountain outside the library. Researcher Avatars, respond: What should you do?

You wait for moonlight since the Oracle is more willing to appear in the shadows of night. But instead of the Oracle, an arm slowly emerges from the water, and in its dripping hand, a sword! Wait, the moonlight confused you-it's not a sword, the hand is holding a number-two pencil, as if to suggest that assessment of library skills is best accomplished by Scantron-like multiple-choice tests! Libraryhero Advocates, what do you do? Do you accept the soggy-handed pencil and reduce skills assessment to standardized testing?

You take the pencil, snap it in half, and throw the pieces in the water; the hand makes a rude gesture and resubmerges into shadowy murk. But your spirit is light and your mind is on fire, certain that library skills are better developed and assessed through desiredriven learning. But an important key is missing - how can both students and librarians know and show the skills they are developing? Wait, on your right, something glinting on the ground-it's a key, a key to the restricted section of the library! Who could have dropped it here? Rule-breaker heroes-do you use the key?

The door to the restricted section groans on its hinges as you brush aside dangling cobwebs and enter. No one here so late at night to catch you in this indiscretion-you pull a worn tome simply titled Secrets from the dusty shelf and like a chiropractor crack its spine. The book opens to an illustrated page, a drawing of a student-a weeping student-and intuitively you know she weeps because she can neither know nor show all the skills for info literacy she's been acquiring. You turn the page-behold, the same student, only now she beams! Across her chest she wears a sash, a sash that proudly bears insignias denoting various skills-a researcher badge, a media 
literacy badge, a shining Plagiarism Expert badge! Schrute-heroes, you're suddenly struck with an idea for how to assess information literacy, how to empower students and librarians to know and to show skills and competencies-what is this grand idea you've had? Is there room in our libraries for badging as a gamified means of info literacy skills assessment?

A light flickers on in a distant hallway-footsteps swiftly approach: clompy, clompy, clomp clomp clomp (no one should be here at this hour!). Panic surges: what if someone finds you in the restricted section? Wait, you know those footsteps-the hollow thuds of your Director. Mashup-heroes: What do you do? Do you tell your Director your idea for assessing information literacy, or do you hide and wait for daylight?

Your Director is excited to hear your idea. As a Researcher-herotype, your Director would like to know if there is any empirical evidence about the efficacy of badging and gamification in libraries. Hero, you know what to do next...

Heroic reader, thanks for playing. Gamification is the application of game-design principles to non-game contexts; gameful design incorporates basic game architecture, story, and aesthetic as central to course design, infusing education with curiosity, imagination, and play. The examples of gamification we've shared-a convergence of curricular and co-curricular experiences-demonstrate how gameful design yields whole-person, transformational, and enjoyable learning.

\section{SELECT RESOURCES}

Bell, Kevin. 2018. "Gameful Design: A Potential Game Changer.” Educause Review (May/June): 41-48.

Campbell, Joseph. 2008. The Hero with a Thousand Faces. Novato, CA: New World Library.

Cohen, Aaron M. 2011. "The Gamification of Education.” Futurist, 45(5), 16.

Crockett, Zachary, and Javier Zarracina. 2016. "How the Zombie Represents America's Deepest Fears: A Sociopolitical History of Zombies, from Haiti to The Walking Dead.” Vox, October 31, 2016. https://www.vox.com/policy-and-politics/2016/10/31/13440402/ zombie-political-history. 
Huizinga, Johan. 2014. Homo Ludens: A Study of the Play-element in Culture. Boston: Beacon.

Kapp, Karl M. 2012. The Gamification of Learning and Instruction: Game-Based Methods and Strategies for Training and Education. San Francisco, CA: Pfeiffer.

Lameras, Petros, Sylvester Arnab, Ian Dunwell, Craig Stewart, Samantha Clarke, and Panagiotis Petridis. 2017. "Essential Features of Serious Games Design in Higher Education: Linking Learning Attributes to Game Mechanics." British Journal of Educational Technology 48 (4): 972-94.

Lewis, Clive Staples. 2009. The Abolition of Man. New York: HarperCollins.

McGonigal, Jane. 2011. Reality is Broken: Why Games Make Us Better and How They Can Change the World. New York: Penguin Press.

Rūmī, Jalāl al-Dīn. 2004. The Essential Rumi. Translated by Coleman Barks. New York: HarperCollins.

Taylor, Barbara Brown. 2020. Holy Envy: Finding God in the Faith of Others. San Francisco: HarperOne. 